\author{
Working Paper No. 228 \\ Anti-Poverty Effectiveness of Taxes \\ and Income Transfers in \\ Welfare States \\ Hwanjoon Kim
}
Maxwell School of Citizenship and Public Affairs
Syracuse University
Syracuse, New York 13244-1020

\title{
March 2000
}

LIS is a division of the Center for the Study of Population, Poverty and Public Policy (CEPS)/International Networks for Studies in Technology, Environment, Alternatives, Development (INSTEAD) in Differdange, Luxembourg. 


\title{
Anti-Poverty Effectiveness of Taxes and Income Transfers in Welfare States
}

\author{
Hwanjoon Kim \\ Ph.D. Candidate, \\ School of Social Work \\ University of Wisconsin-Madison
}

March, 2000 


\begin{abstract}
This study aims to compare the anti-poverty effectiveness of taxes and income transfers among western welfare states. It is shown that a country's poverty outcome can be decomposed into the level of market-generated poverty, the overall level of welfare efforts, and the poverty reduction efficiency of taxes and transfers. Using the LIS micro data, the decomposition analysis suggests that welfare states differ widely in respect to the anti-poverty effectiveness of taxes and transfers and that cross-national variation in anti-poverty effectiveness is mainly attributed to differences in the level of welfare efforts, rather than to differences in the poverty reduction efficiency.
\end{abstract}




\section{Introduction}

Recently, there has been an increasing academic attention to comparative study on the welfare state. Although large differences in political, social, and cultural institutions across countries may hinder drawing definite conclusions from cross-national comparisons, comparative studies may nevertheless have several merits for social science and policy research. The objectives of comparative study are to describe the seriousness of social problems common in every country to be compared, to find out institutional and behavioral factors that contribute to the problems, and to evaluate the effectiveness of policies to solve the problems (Hauser, 1992). These efforts of comparative study help us judge a country's relative achievement in solving social problems common in every country (Smeeding, 1992). Moreover, cross-national differences in dealing with similar social problems can offer a "natural experiment" (Lisle, 1985; Smeeding, 1992). Therefore, by specifying diverse policy options in different countries, and by providing the socio-economic consequences of different policies, comparative studies can improve knowledge in policy analysis (Wilensky, Luebbert, Hahn, and Jamieson, 1987).

Western capitalist societies are generally referred to as the welfare state, the essence of which is active government responsibility to secure a minimum standard of living. In spite of the considerable welfare efforts of the government, however, a substantial number of citizens in welfare states do not possess a socially-accepted minimal standard of living. Increasing the living standard of these people - the least well-off members of a society—is of continuing concern of social policy in welfare states, as well as in developing countries.

Although poverty alleviation is an important aim of social policy in every welfare state, the institutional features of welfare policies vary greatly across welfare states. Reflecting each 
country's peculiar historical, ideological, political, and socio-economic backgrounds, different regimes of welfare policies tend to yield different poverty outcomes. The aim of this study is to compare the anti-poverty effectiveness of welfare states. Among diverse aspects of social welfare policies, a particular concern is on the role of taxes and income transfers in poverty alleviation. Major questions to be answered in this study are as follows: How much do the extents and trends of poverty differ among welfare states? In which countries do taxes and transfers more effectively alleviate poverty? What characteristics of the tax-transfer system affect poverty reduction effectiveness? Which characteristics are more important in explaining cross-national variation of poverty? And what are the trends of these characteristics of the taxtransfer system throughout the 1980s and early 1990s? ${ }^{1}$

Prior studies in this area fail to provide sufficient answers to the above questions, either because they do not deal directly with those questions or because they suffer from methodological deficiencies. This study tries to expand existing studies to provide more informative and extensive answers to those questions. In this study, the commonality and difference of welfare states are summarized by two major features of the tax-transfer system: 1) the overall level of taxes and transfers (the size of the welfare state) and 2) the universality versus selectivity of the tax-transfer system (poverty reduction efficiency). Then, it turns out that a country's poverty outcome can be decomposed into three components: 1) the level of poverty generated from the market economy, 2) the size of the welfare state, and 3) poverty reduction efficiency. Using the Luxembourg Income Study (LIS) micro data, this study analyzes the crossnational variations and trends of these components. 


\section{Prior Studies}

Recently, a number of studies has conducted cross-national comparisons of poverty using micro income data such as the LIS database (e.g., among others, Atkinson, Rainwater, and Smeeding, 1995; Burniaux, Dang, Fore, Förster, d'Ercole, and Oxley, 1998; Förster, 1993; Jäntti and Danziger, 1998; Mitchell, 1991). In spited of differences in the measurement of poverty and the database used, these studies have consistently found that there is a large difference in the extent of poverty among welfare states. In general, Scandinavian and Benelux countries have the lowest extents of poverty, followed by continental European countries. English-speaking countries have relatively higher extents of poverty. Among them, the extent of poverty is the highest in the United States.

Why is there a wide variation in poverty among welfare states? Traditionally, welfare state typologies have been largely based on the overall level of social expenditure. Studies have found a strong relationship between the level of social expenditure and poverty incidence (Förster, 1993; Mitchell, 1991). In other words, countries with a higher level of welfare expenditure are likely to have a lower extent of poverty. However, welfare expenditure as a whole is not the only determinant of a country's poverty outcome. At least three more factors should be taken into consideration.

First, differences in the market (private) economy—primarily in inequality in the labor market-are obviously an important source of cross-national variation in poverty. Second, differences in the tax system are not reflected in the traditional measure of welfare expenditure. A country spending relatively less money on its welfare programs may make a greater effort toward redistribution through its tax system. Moreover, countries with a higher level of welfare 
expenditure are likely to levy greater tax burdens on their citizens. From the standpoint of households, a certain amount of tax reduction gives basically the same benefits as the same amount of transfer does. Therefore, differences in the tax system should be taken into account in the assessment of the anti-poverty effect of the welfare state. Third, the traditional measure ignores the distributional aspect of welfare expenditure. The same level of welfare spending may reduce poverty by quite different extents, depending on how it is distributed. Country A may spend most of its welfare expenditures for the poor, whereas in country B the non-poor are the primary beneficiaries of welfare benefits. Other things being equal, the extent of poverty would be lower in country A than in country B.

To take into account the distributional features of welfare expenditure, studies have used the concept of "efficiency". Weisbrod (1969) was among the first who introduced the concept of efficiency in analyzing the anti-poverty effects of welfare transfers. Weisbrod proposed the concept of 'target efficiency', which is defined by the ratio of benefits going to the target group (i.e., the poor) to total benefits. The empirical model for analyzing efficiency is further developed by Beckerman (1979). Beckerman used the term 'poverty reduction efficiency', which is defined by the proportion of welfare transfers actually contributing to the reduction of poverty. Figure 1 explains the Beckerman's model of poverty reduction efficiency.

The horizontal axis represents individuals (or households) arrayed in the ascending order of their incomes and the vertical axis represents their incomes. The solid line refers to pretransfer income, while the dotted line represents post-transfer income. Given the poverty line, the pre-transfer poverty gap is $A+D$. The total amount of transfers is $A+B+C$. Among the transfer benefits, $\mathrm{A}+\mathrm{B}$ amount is received by the pre-transfer poor, while $\mathrm{C}$ amount is received by the pre-transfer non-poor. Beckerman refers to the proportion of benefits received by the pre-transfer 
poor as the vertical expenditure efficiency (VEE). In the figure, the VEE is given by $(\mathrm{A}+\mathrm{B}) /(\mathrm{A}+\mathrm{B}+\mathrm{C})$. Although $\mathrm{B}$ amount is received by the pre-transfer poor, it is overpaid and increases the income of the recipients to higher than the poverty line. Beckerman refers to this amount as "spillover". Only the A amount actually contributes to reducing the pre-transfer poverty gap. Therefore, the poverty reduction efficiency is given by $A /(A+B+C)$. Finally, the post-transfer poverty gap is represented by $\mathrm{D}$, and the overall poverty reduction effectiveness (the proportion of the pre-transfer poverty gap reduced by transfers) is given by $A /(A+D)$.

\section{Figure 1. Beckerman’s Model of Poverty Reduction Efficiency}

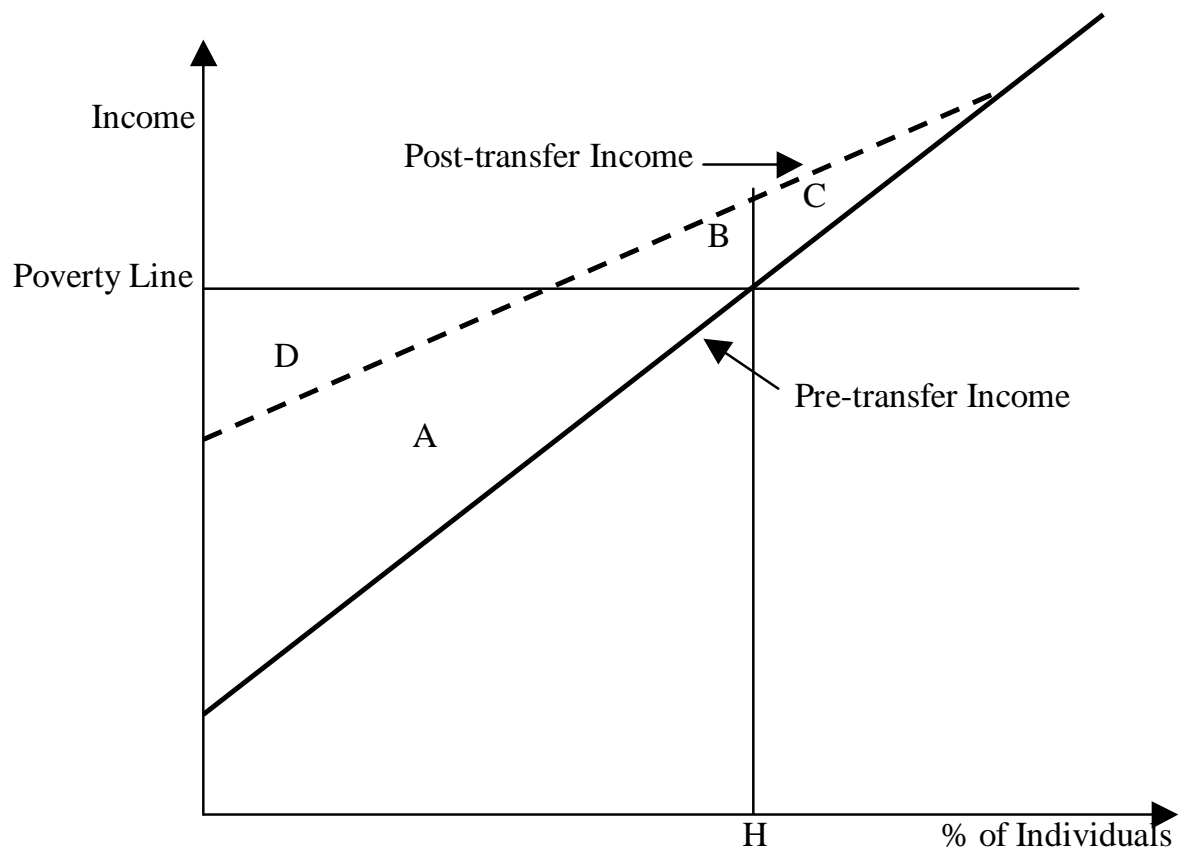

In sum, the extent of poverty in a country is determined by three major factors: 1) the extent of poverty generated from the market economy, 2) the overall level of welfare expenditure and the amount of tax claw-backs, and 3) the poverty reduction efficiency of taxes and welfare benefits. What are relative contributions of these factors to cross-national variation in poverty? 
As mentioned above, the majority of studies in this area have focused on the level of welfare expenditure. The issue of poverty reduction efficiency is largely neglected in these studies. Up to date, few cross-national studies have analyzed the effects of the above factors simultaneously. Among the few, Mitchell (1991) and Mitchell, Natsem, and Gruen (1994) analyzed crossnational statistical relationship among pre-tax-transfer poverty, post-tax-transfer poverty ${ }^{2}$, and the size and the efficiency of the tax-transfer system. Mitchell (1991) found the following relationship.

$$
\begin{gathered}
P_{\text {post }}=-0.09+1.02 * P_{\text {pre }}-0.99 * E S S / G D P \quad \mathrm{R}^{2}=0.98 \\
(\mathrm{t}=20.3) \quad(\mathrm{t}=18.5)
\end{gathered}
$$

where ESS represents effective social expenditure (defined by the amount of social expenditure multiplied by Beckerman's measure of poverty reduction efficiency), $P_{\text {post }}$ and $P_{\text {pre }}$ are the posttax-transfer poverty gap and the pre-tax-transfer poverty gap, respectively. Similarly, Mitchell et al. (1994) provides the following result.

$$
\begin{aligned}
& P_{\text {post }}=9.89-1.64 * \text { Generosity }-0.13 * \text { Efficiency } \quad \mathrm{R}^{2}=0.72 \\
& (\mathrm{t}=7.2) \quad(\mathrm{t}=5.5)
\end{aligned}
$$

where the generosity is measured by the ratio of total social transfers to the pre-transfer poverty gap. Very high $\mathrm{R}^{2} \mathrm{~s}$ in both regression equations imply that cross-national variation in the posttax-transfer poverty gap is mostly attributed to the variations in three components: the pre-taxtransfer poverty gap, the overall level (size), and the poverty reduction efficiency of taxes and transfers.

Although these two studies provide useful information on the relationship among the determinants of post-tax-transfer poverty, they suffer from several methodological deficiencies. First of all, they fail to separate the effects of three components, by combining two factors in 
each equation. The ESS in the first equation combines the size and the efficiency of taxes and transfers. The generosity in the second equation combines the pre-tax-transfer poverty gap and the size of tax-transfers. As a result, they could not provide the relative importance of each component in explaining cross-national variation in post-tax-transfer poverty. Second, as shown later, the post-tax-transfer poverty gap can be decomposed mathematically—not statisticallyinto the three components. Third, the measure of social expenditure in the above regression models does not reflect cross-national difference in the tax system. Finally, in measuring poverty, they use the family as a unit of analysis, whereas theoretical arguments are in favor of the individual as a unit of analysis.

\section{Data and Methods}

For the empirical analyses, this study primarily uses the LIS database. The most recent LIS data sets currently available are the wave 4 (1993-1997) database. However, some individual countries' data sets in the wave 4 database are currently being reviewed and not available for public use. For these countries, this study uses the wave 3 (1989-1992) database. Overall, 22 individual countries are included either in the wave 3 or in the wave 4 database. Among the 22 countries, 5 former-communist countries and 2 non-western countries are not analyzed in this study $^{3}$. Moreover, 4 countries are excluded in the analysis, because some critical income variables are not available in the data of these countries ${ }^{4}$. In sum, this study analyzes 38 individual data sets from 11 western welfare states ${ }^{5}$.

A problem faced in the cross-national comparison of poverty is the measurement of poverty. There have been controversial arguments on the issues in the measurement of poverty. 
These arguments have their own merits and shortcomings, and there has been little professional consensus on the theoretical superiority of a particular way of poverty measure. Moreover, the availability of reliable data restricts what is possible to do, which is especially critical in crossnational study.

Specific methods of poverty measurement adopted in this study are as follows. First, the poverty threshold is defined by $50 \%$ of the median equivalent disposable income of households ${ }^{6}$. Second, for the equivalent scale, this study uses the one recommended by the National Research Council in the United States (Citro and Michael, 1995) ${ }^{7}$. Third, the vast majority of studies in this area have used the head-count ratio (or poverty rate) as a summary poverty index. Although the head-count ratio is simple and easy to understand, it has several shortcomings especially critical for the cross-national comparison of the anti-poverty effects of taxes and transfers ${ }^{8}$. In this study, the extent of poverty is presented by the aggregate poverty gap as a percentage of post-tax-transfer income (hereafter, poverty gap ratio) ${ }^{9}$.

Figure 2 shows the basic analytical framework of this study. The final poverty outcome (post-tax-transfer poverty) of a country is determined by two factors: 1) the level of poverty generated from the market economy (pre-tax-transfer poverty), and 2) the extent of poverty reduced through taxes and transfers (poverty reduction effectiveness). The poverty reduction effectiveness, again, depends on two major characteristics of the tax-transfer system: 1) the overall level of taxes and transfers (the size of the welfare state), and 2) the degree of poverty reduction efficiency. The following are the definitions and measurements of these key concepts.

As described above, pre-tax-transfer poverty and post-tax-transfer poverty are the extents of poverty estimated from market income and disposable income, respectively. They are presented in terms of the poverty gap ratio. The difference between pre-tax-transfer poverty and 
post-tax-transfer poverty is defined as the poverty reduction effectiveness of taxes and transfers. Poverty reduction effectiveness has been typically presented as a relative concept or a percentage reduction ${ }^{10}$. In this study, poverty reduction effectiveness is presented with an absolute term (i.e., the absolute amount of poverty gap ratio reduced by taxes and transfers). This helps us to decompose the post-tax-transfer poverty into its components.

\section{Figure 2. Analytical Framework of the Study}

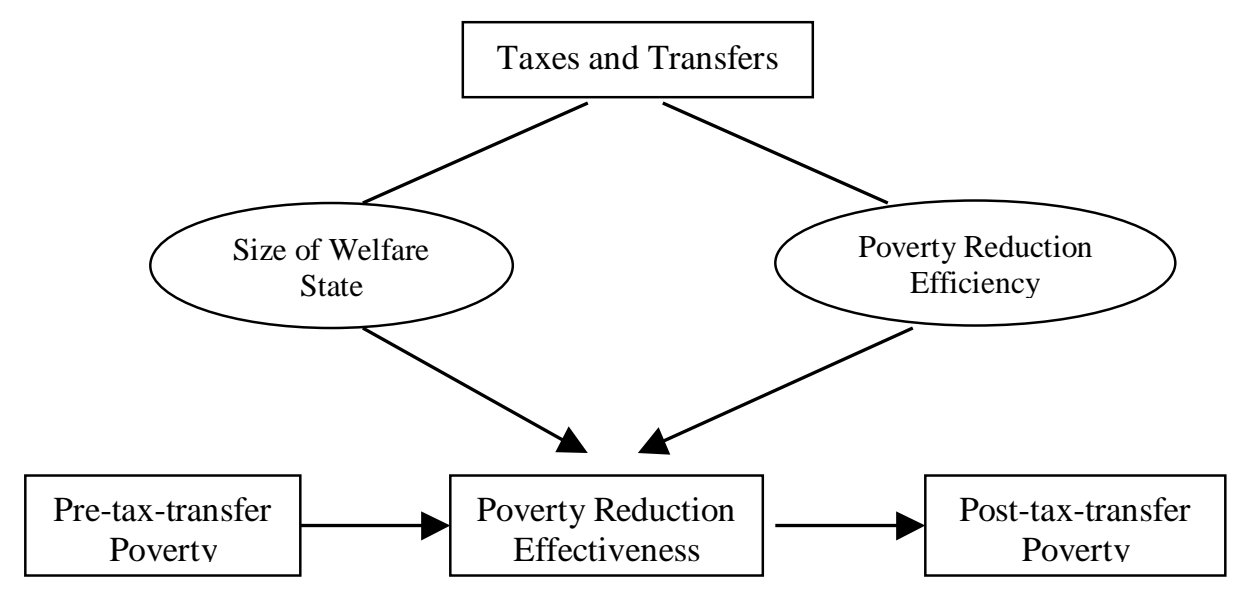

At a macro-level, the size of the welfare state has been typically measured by the amount of welfare expenditure as a percentage of GDP. A corresponding micro measure is the average proportion of transfer income to total income. However, these two measures are less informative as a determinant variable of post-tax-transfer poverty because they do not take into account of tax claw-backs. In this study, the size of the welfare state is measured by the average amount of positive net transfers (i.e., transfer income net of taxes) ${ }^{11}$ per equivalent adult ${ }^{12}$.

For the measurement of poverty reduction efficiency (PRE), this study follows the Beckerman's definition of PRE. Again, a drawback of Beckerman's model is that it ignores tax claw-backs. To take tax claw-backs into account, the solid line and the dotted line in Figure 1 
need to be changed to represent pre-tax-transfer income and post-tax-transfer income, respectively. Correspondingly, the area of $\mathrm{A}+\mathrm{B}+\mathrm{C}$ should represent positive net transfers. In sum, the poverty reduction efficiency is defined by the proportion of positive net transfers contributing to the reduction of the pre-tax-transfer poverty gap.

When the size and the poverty reduction efficiency of taxes and transfers are defined as the above, post-tax-transfer poverty can be decomposed as follows:

$$
\begin{aligned}
P_{\text {post }}\left(\frac{D}{G}\right) & =P_{\text {pre }}\left(\frac{A+D}{G}\right)-\text { effectiveness }\left(\frac{A}{G}\right) \\
& =P_{\text {pre }}-\text { size }\left(\frac{A+B+C}{G}\right) \times \text { efficiency }\left(\frac{A}{A+B+C}\right)
\end{aligned}
$$

where $P_{\text {pre }}$ and $P_{\text {post }}$ are the pre-tax-transfer poverty gap and the post-tax-transfer poverty gap as a percentage of the sum of post-tax-transfer incomes, $G$ is the sum of post-tax-transfer incomes of households, and $A, B$, and $C$ are the areas shown in Figure 1.

Conceptually, this decomposition seems to be straightforward. In practice, however, equation (1) is often not satisfied. This is primarily because of tax claw-backs. If tax claw-backs are not subtracted, post-transfer income is always higher than-or at least equal to-pre-transfer income. In other words, household-level post-transfer poverty gap cannot exceed the pre-transfer poverty gap in every household. In this case, the difference between $P_{\text {pre }}$ and $P_{\text {post }}$ (poverty reduction effectiveness) always equals the product of the size and the efficiency.

On the other hand, if tax claw-backs are taken into account, household-level post-taxtransfer poverty gap may exceed the pre-tax-transfer poverty gap. Some of the pre-tax-transfer poor may pay more taxes than the amount of transfers they receive, although these cases are relatively rare. Also, due to tax claw-backs, some of the pre-tax-transfer non-poor may become 
post-tax-transfer poor. According to the LIS database, 0.3 (in Belgium and Canada) to 2.3 (in the United States) percentages of households are in the first case and 0.1 (in Australia and Canada) to 1.0 (In the United State) percentages are in the second case. As a result of receiving negative net transfers from the government, household-level poverty gap is increased in these households. Since the tax-transfer system as a whole increases the poverty gap in these households, as well as reduces the poverty gap in other households, overall poverty reduction effectiveness is equal to the amount of reduction in poverty gap net of the amount of increase in poverty gap. Therefore, a complete decomposition is given by:

$$
\begin{aligned}
P_{\text {post }} & =P_{\text {pre }}-\text { overall effectiveness } \\
& =P_{\text {pre }}-\left(\text { poverty reduction effectiveness }-P_{i n c}\right) \\
& =P_{\text {pre }}-\left(\text { size } \times \text { efficiency }-P_{i n c}\right)
\end{aligned}
$$

where $P_{\text {inc }}$ is the amount of poverty gap increased by negative net transfers as a percentage of the sum of post-tax-transfer incomes.

This decomposition allows us to explain the cross-national variation of post-tax-transfer poverty in terms of variations in its components. In other words, it demonstrates the relative contribution of each component to the cross-national variation of post-tax-transfer poverty. The most commonly used measure of variability in statistical analysis is the variance (or the standard deviation). However, a direct comparison of two variances may not be appropriate, if the scales of two variables are different. When the units of measurement are different, the coefficient of variation $(\mathrm{CV})$ is usually employed for the comparison of variability. The $\mathrm{CV}$ is given by the ratio of the standard deviation to the mean. Using the $\mathrm{CV}$, this study compares cross-national variations in pre-tax-transfer poverty, poverty reduction effectiveness, the size, and the efficiency of taxes and transfers. 


\section{Results}

Figure 3 shows the extent of poverty in 11 western welfare states. Here, the extents of poverty are measured by the poverty gap ratio ${ }^{13}$. The whole bar indicates the pre-tax-transfer poverty gap ratio in each country, and the left part of each bar indicates the post-tax-transfer poverty gap ratio. As shown in the figure, there is a large difference in the extent of poverty among welfare states. The largest post-tax-transfer poverty gap ratio (2.37\% in the United States) is about 6 times as great as the smallest poverty gap ratio $(0.42 \%$ in Finland). Continental European countries have a relatively lower extent of poverty than English-speaking countries.

\section{Figure 3. Extents of Poverty in Welfare States}

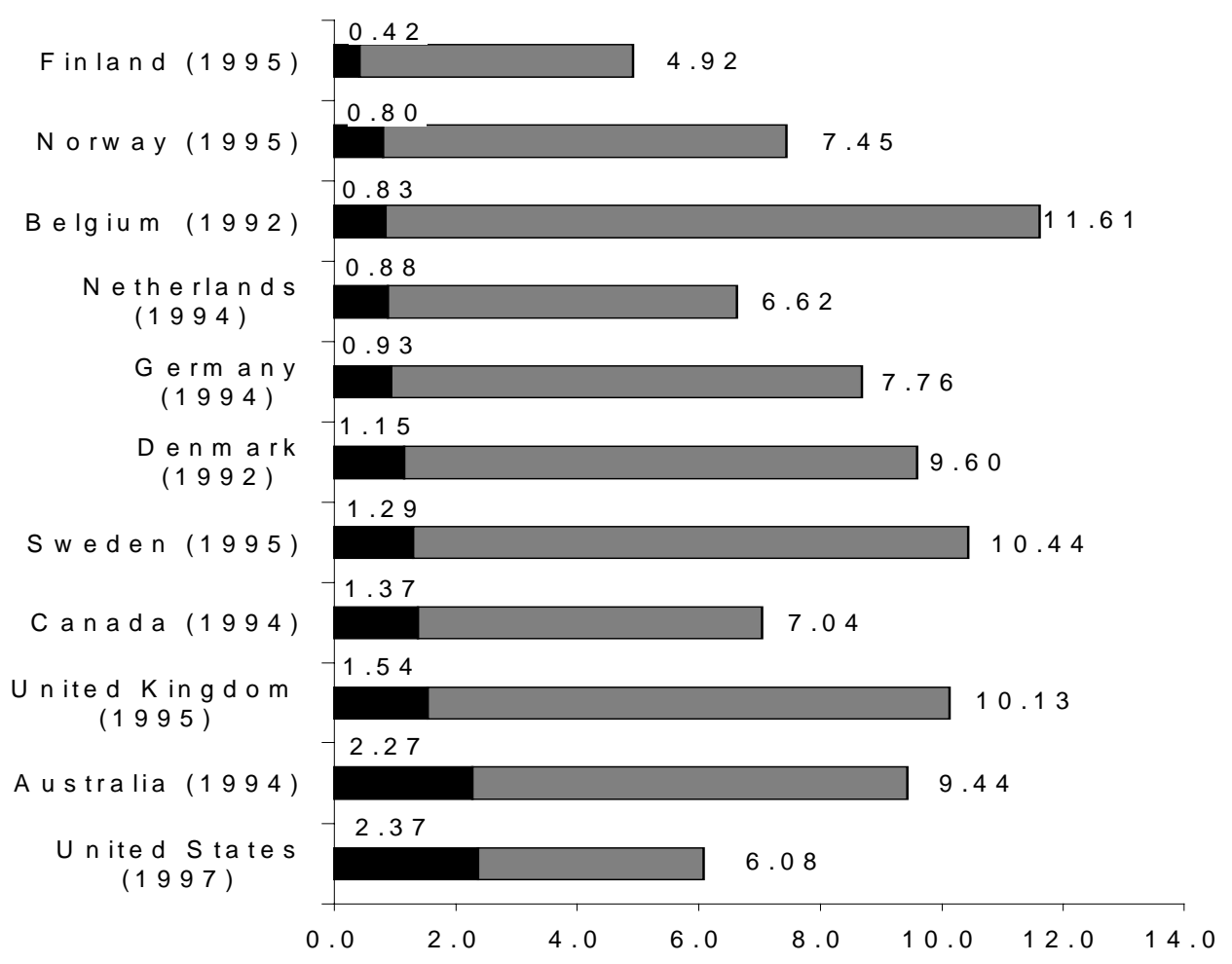

* Countries are sorted by the ascending order of the post-tax-transfer poverty gap ratio. Source: Author's figuration from the LIS database. 
Table 1 shows the decomposition results. The second column shows the pre-tax-transfer poverty gap ratio $\left(P_{\text {pre }}\right)$. The highest $P_{\text {pre }}$ is $11.6 \%$ in Belgium, whereas Finland has the lowest $P_{\text {pre }}, 4.9 \%$. The average $P_{\text {pre }}$ among 11 countries is $8.4 \%$. The third column shows increases in the poverty gap ratio by negative transfers. Among about $0.4 \%$ (in Canada) to $3.3 \%$ (in the United States) of households, the post-tax-transfer poverty gap exceeds the pre-tax-transfer poverty gap, because tax liabilities are greater than transfer benefits in these households. However, the total amount of increase in the poverty gap in these households is negligibly small. It accounts for only 0.02 to $0.11 \%$ of total post-tax-transfer income, or 0.2 to $1.1 \%$ of the pre-taxtransfer poverty gap ratio.

\section{Table 1. Decomposition of Post-Tax-Transfer Poverty Gap}

\begin{tabular}{|l|c|c|c|c|c|c|}
\hline \multicolumn{1}{|c|}{ Country } & $\mathbf{P}_{\text {pre }}{ }^{\mathbf{1}}$ & $\mathbf{P}_{\text {inc }}{ }^{\mathbf{2}}$ & $\mathbf{P}_{\text {post }}{ }^{\mathbf{3}}$ & $\mathbf{P}_{\text {eff }}{ }^{4}$ & Size $^{\mathbf{5}}$ & Efficiency $^{\mathbf{6}}$ \\
\hline Australia (1994) & 9.44 & 0.02 & 2.27 & 7.19 & 10.2 & 70.6 \\
Belgium (1992) & 11.61 & 0.02 & 0.83 & 10.80 & 20.6 & 52.5 \\
Canada (1994) & 7.04 & 0.01 & 1.37 & 5.67 & 10.8 & 52.5 \\
Denmark (1992) & 9.60 & 0.07 & 1.15 & 8.52 & 15.1 & 56.3 \\
Finland (1995) & 4.92 & 0.06 & 0.42 & 4.56 & 10.5 & 43.5 \\
Germany (1994) & 8.68 & 0.05 & 0.93 & 7.80 & 16.8 & 46.4 \\
Netherlands (1994) & 6.62 & 0.06 & 0.88 & 5.80 & 11.6 & 50.2 \\
Norway (1995) & 7.45 & 0.05 & 0.80 & 6.69 & 13.3 & 50.4 \\
Sweden (1995) & 10.44 & 0.11 & 1.29 & 9.25 & 22.5 & 41.1 \\
U.K. (1995) & 10.13 & 0.11 & 1.54 & 8.69 & 14.1 & 61.8 \\
U.S.A. (1997) & 6.08 & 0.07 & 2.37 & 3.78 & 7.4 & 51.3 \\
& & & & & & \\
Mean & 8.36 & 0.06 & 1.26 & 7.16 & 13.9 & 52.4 \\
CV & 0.238 & 0.547 & 0.461 & 0.282 & 0.317 & 0.151 \\
\hline
\end{tabular}

1. Pre-tax-transfer poverty gap as a percentage of total post-tax-transfer income.

2. The amount of an increase in poverty gap through negative net transfers as a percentage of total post-taxtransfer income.

3. Post-tax-transfer poverty gap as a percentage of total post-tax-transfer income.

4. The amount of reduction in poverty gap through positive net transfers as a percentage of total post-tax-transfer income.

5. The size of the welfare state, defined by the sum of positive net transfers as a percentage of total post-taxtransfer income.

6. Poverty reduction efficiency, defined by the proportion of positive net transfers contributing to reduce pre-taxtransfer poverty gap.

Source: Author's calculation from the LIS database. 
Column 4 shows the post-tax-transfer poverty gap ratio $\left(P_{\text {post }}\right)$. As shown in Figure 3 and Table $1, P_{\text {post }}$ is substantially less than $P_{\text {pre }}$ in every country, implying that taxes and transfers in welfare states achieve a substantial reduction of poverty. The largest difference between $P_{p r e}$ and $P_{p o s t}$ is achieved in Belgium, where $P_{p r e}$ is $11.61 \%$ and $P_{p o s t}$ is only $0.83 \%$. In a relative term, this is a $93.1 \%$ [(11.61-0.83)/11.61] reduction of the poverty gap ratio. On the other extreme, in the United States, the difference between $P_{\text {pre }}$ and $P_{\text {post }}$ is $3.71 \%$, or a $61.0 \%$ reduction of $P_{\text {pre }}$.

Cross-national variation in $P_{\text {post }}$ is greater than variation in $P_{\text {pre }}$. The CV of $P_{\text {post }}$ is 0.461 , whereas the CV of $P_{\text {pre }}$ is 0.238 . The largest $P_{\text {post }}$ (2.37\% in the United States) is about 5.6 times as great as the smallest $P_{\text {post }}(0.42 \%$ in Finland $)$. In respect to $P_{\text {pre }}$, the largest $P_{\text {pre }}(11.61 \%$ in Belgium) is 2.4 times as great as the smallest $P_{\text {pre }}(4.92 \%$ in Finland).

Column 5 in Table 1 shows the poverty reduction effectiveness $\left(P_{e f f}\right)$ of positive net transfers. It is defined by the absolute amount of the poverty gap ratio reduced by positive net transfers. As explained in Section 3, it is equal to the difference between Column $(2+3)$ and Column 4. However, since the amounts of the poverty gap ratio increased through negative net transfers to the poor $\left(P_{i n c}\right.$, in Column 3$)$ are negligibly small, $P_{\text {eff }}$ is approximately the same as the difference between $P_{\text {pre }}$ and $P_{\text {post. }} P_{\text {eff }}$ varies from $3.78 \%$ (in the United States) to $10.80 \%$ (in Belgium).

Which of the two factors- $P_{p r e}$ and $P_{\text {eff }}-$ is more important in explaining cross-national variation of $P_{\text {post }}$ ? Figure 4 shows the bi-variate relationships between $P_{p o s t}$ and $P_{\text {eff }}$ and between $P_{p o s t}$ and $P_{\text {pre }}$. As suggested in the figure, both $P_{\text {eff }}$ and $P_{\text {pre }}$ do not have any strong relationship with $P_{p o s t}$. Since $P_{\text {post }}$ is approximately a linear combination of $P_{p r e}$ and $P_{e f f}$, it is counter-intuitive that both $P_{\text {pre }}$ and $P_{\text {eff }}$ are not related to $P_{\text {post }}$. This surprising result is mainly due to a very high 
correlation between $P_{\text {pre }}$ and $P_{\text {eff }}(\mathrm{r}=0.958)$. The implications of this strong relationship between $P_{\text {pre }}$ and $P_{\text {eff }}$ are discussed in the conclusion section.

Figure 4. Relationships between $\boldsymbol{P}_{p o s t}$ and $\boldsymbol{P}_{\text {pre }}$ and between $\boldsymbol{P}_{\text {post }}$ and $\boldsymbol{P}_{\text {eff }}$
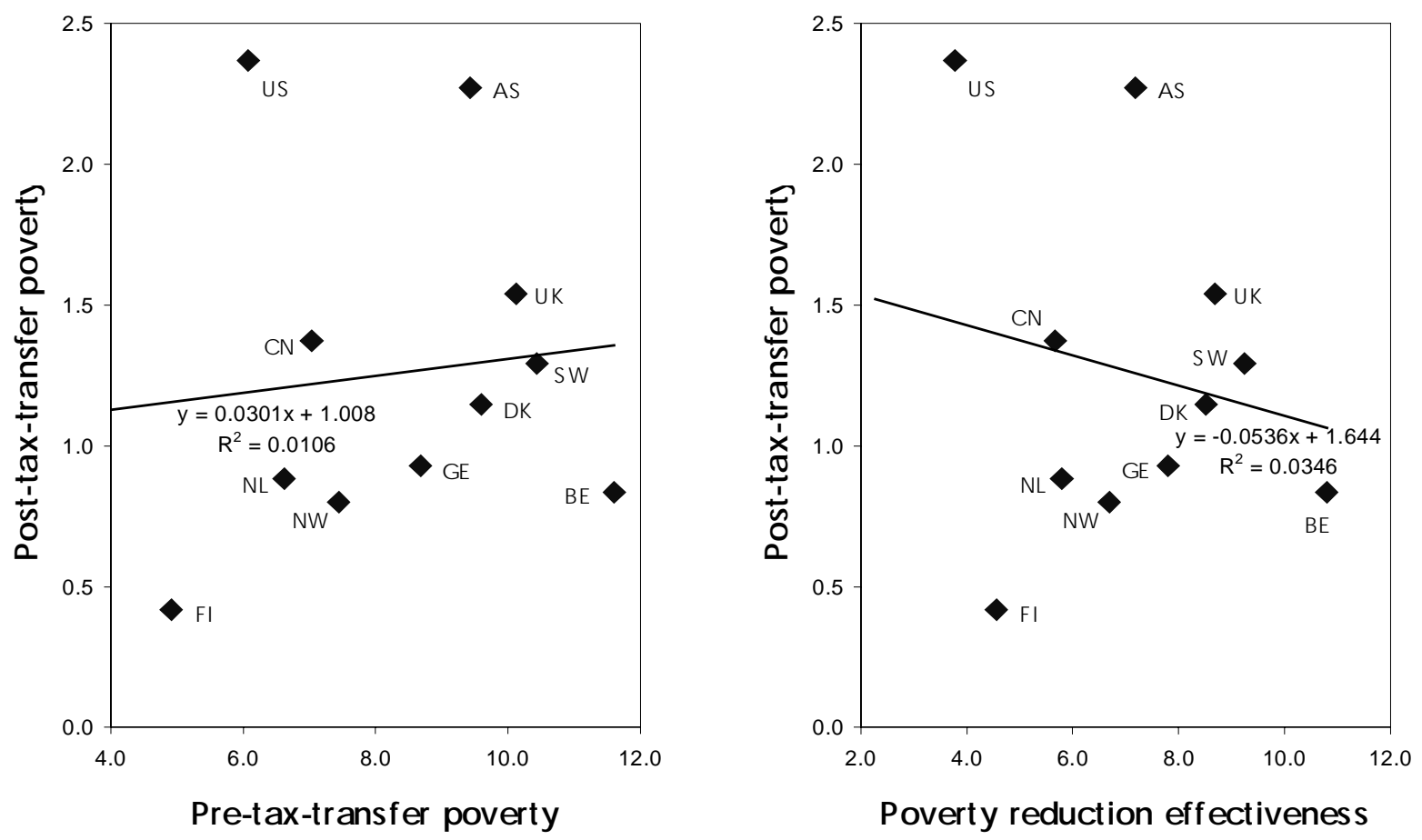

Source: Author's figuration from Table 1.

Since $P_{\text {post }}$ is a linear combination of $P_{\text {pre }}, P_{\text {inc }}$, and $P_{\text {eff, }}$, the variation of $P_{\text {post }}$ can be decomposed into the variations of $P_{p r e}, P_{i n c}, P_{e f f}$, and the interaction terms between two of these three variables. In other words, the decomposition equation (2) implies the following equation:

$$
\begin{aligned}
V_{\text {post }}^{2}= & a^{2} V_{\text {pre }}^{2}+b^{2} V_{\text {inc }}^{2}+c^{2} V_{e f f}^{2} \\
& +2 a b \rho_{\text {pre, inc }} V_{\text {pre }} V_{\text {inc }}-2 b c \rho_{\text {inc }, \text { eff }} V_{\text {inc }} V_{\text {eff }}-2 c a \rho_{\text {eff }, \text { pre }} V_{\text {eff }} V_{\text {pre }}
\end{aligned}
$$

where $V_{\text {post }}, V_{\text {pre }}, V_{\text {inc }}, V_{\text {eff }}$ are the $\mathrm{CV}$ of $P_{\text {post }}, P_{\text {pre }}, P_{\text {inc }}$, and $P_{\text {eff }}$, respectively, $\rho$ 's are the correlation coefficients between two variables, and $a=\mu_{\text {pre }} / \mu_{p o s t}, b=\mu_{\text {inc }} / \mu_{\text {post }}$, and $c=\mu_{\text {eff }} / \mu_{\text {post }}$. 
According to Table 1, the $\mathrm{CV}$ of the $P_{\text {post }}$ is decomposed as:

$$
\begin{aligned}
(0.461)^{2}= & (6.637)^{2}(0.238)^{2}+(0.045)^{2}(0.547)^{2}+(5.681)^{2}(0.282)^{2}+ \\
& +2(6.637)(0.045)(0.101)(0.238)(0.547)-2(0.045)(5.681)(0.109)(0.547)(0.282) \\
& -2(5.681)(6.637)(0.958)(0.282)(0.238) \\
\text { or, } 0.213= & 2.495+0.001+2.567+0.008-0.009-4.849
\end{aligned}
$$

Equation (4) provides the relative contribution of each component to the variation of $P_{\text {post. }} P_{\text {inc }}$ and its interaction terms with other variables do not have substantial effects on the variation of $P_{\text {post }}$. Therefore, the variation of $P_{\text {post }}$ is primarily attributed to $P_{\text {pre }}, P_{\text {eff }}$, and the interaction term of these two variables. Among them, the relative contributions of $P_{\text {pre }}$ and $P_{\text {eff }}$ are about the same (2.495 and 2.567). Moreover, since $P_{\text {pre }}$ and $P_{\text {eff }}$ are highly correlated to each other, the interaction term has a substantial effect on the variation of $P_{\text {post }}(-4.849)$.

Poverty reduction effectiveness $\left(P_{\text {eff }}\right)$ in Column 5 is equal to the product of the size of the welfare state (Column 6) and the poverty reduction efficiency (Column 7). Of these two components of $P_{\text {eff, }}$ the cross-national variation of the size is much larger than the variation of the efficiency. The CV of the size is 0.317 , whereas the CV of the efficiency is only 0.151. Moreover, as shown in Figure 5, the correlation between the efficiency and $P_{\text {eff }}$ are very low $(r=0.135)$. On the other hand, there is a strong correlation between the size and $P_{\text {eff }}(r=0.873)$.

To assess the relative contribution of explanatory variables to the variance in the dependent variable, the beta regression is often used. Regression coefficients in their unstandardized form tell us nothing about the relative contribution of explanatory variables, because the magnitude of them depends on the unit of measurement. In the beta regression, all variables are in their standardized $z$ score form, and hence, unit-free. The relative importance of two explanatory variables can be obtained by taking the ratio of the squares of the beta regression coefficients ${ }^{14}$. Based on Table 1, the result of the beta regression is as follows: 


$$
\text { Effectiveness }=1.044 * \text { Size }+0.496 * \text { Efficiency } \quad\left(R^{2}=0.978\right)
$$

(0.053) (0.053)

\section{Figure 5. Relationships between Size and Effectiveness $\left(\mathbf{P}_{\text {eff }}\right)$ And between Efficiency and Effectiveness}
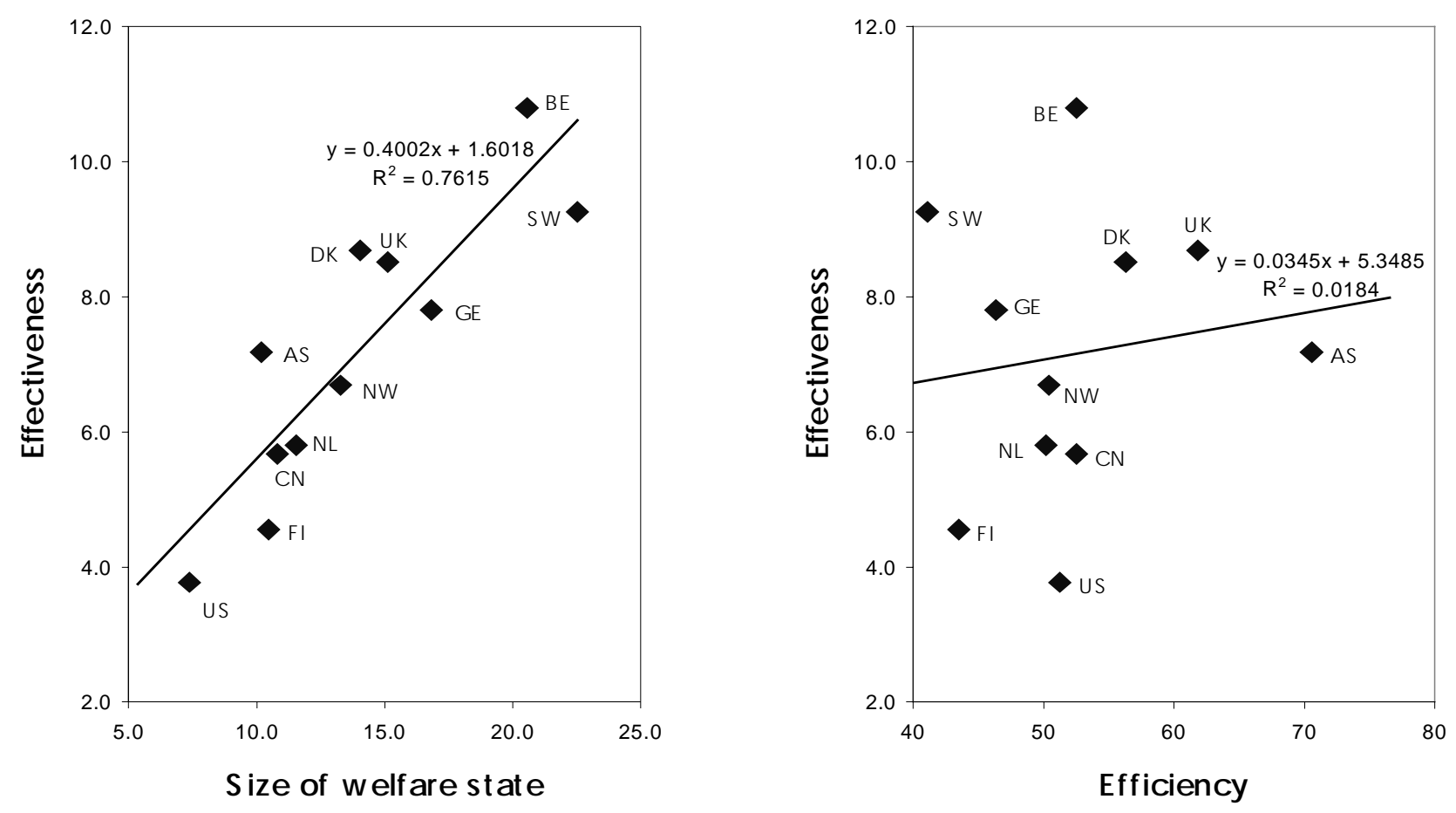

Source: Author's figuration from Table 1.

This result implies that the cross-national variation of $P_{\text {eff }}$ is primarily due to differences in the size of the welfare state rather than due to differences in the poverty reduction efficiency. The relative contribution of the size to the cross-national variation in $P_{\text {eff }}$ is about 4.44 $\left(1.044^{2} / 0.496^{2}\right)$ times as great as the contribution of the efficiency. The decomposition of the CV of effectiveness is helpful to clarify this result. Since the effectiveness is equal to the product of the size and the efficiency, the log of the effectiveness is the sum of the log of the size and the $\log$ of the efficiency. Therefore, the CV of the log of the effectiveness can be decomposed as: 


$$
V_{\text {effect }}^{2}=a^{2} V_{\text {size }}^{2}+b^{2} V_{\text {efficiency }}^{2}+2 a b \rho_{\text {size,efficiency }} V_{\text {size }} V_{\text {efficiency }}
$$

where $V_{\text {effect }}, V_{\text {size }}, V_{\text {efficiency }}$ are the CV's of the log of the poverty reduction effectiveness $\left(P_{\text {eff }}\right)$, of the log of the size of the welfare state, and of the log of the poverty reduction efficiency, respectively, $\rho_{\text {size,efficiency }}$ is the correlation coefficient between the size and the efficiency, and $a=\mu_{\text {size }} / \mu_{\text {effect }}$ and $b=\mu_{\text {efficiency }} / \mu_{\text {effect }}$.

Therefore, according to Table 1 , the $\mathrm{CV}$ of the $\log$ of $P_{\text {eff }}$ is decomposed as:

$$
\begin{aligned}
& (0.157)^{2}=(1.341)^{2}(0.122)^{2}+(0.341)^{2}(0.221)^{2}+2(1.341)(0.341)(-0.309)(0.122)(0.221) \\
& \text { or, } 0.025=0.027+0.006-0.008
\end{aligned}
$$

The decomposition result (6) suggests that to variation in the log of the poverty reduction effectiveness, variation in the log of the size contributes 4.5 times $(0.027 / 0.006)$ as much as variation in the log of the efficiency does.

In sum, the results of the decomposition analysis can be summarized as follows: Crossnational variation in post-tax-transfer poverty is attributed to variation in pre-tax-transfer poverty and the poverty reduction effectiveness of taxes and transfers. The relative contributions of these two factors are about the same. Cross-national variation in the poverty reduction effectiveness is mainly due to variation in the size of the welfare state rather than to the poverty reduction efficiency.

Table 2 shows the trends of the components of $P_{\text {post }}$ during the 1980s and early 1990s. As shown in the table, some welfare states have experienced an increase in $P_{\text {post }}$, while $P_{\text {post }}$ has decreased or remained stable in other countries. The United Kingdom has experienced a sharp increase in $P_{\text {post }}$, from $0.88 \%$ in 1979 to $1.54 \%$ in 1995 (a $76 \%$ increase). Sweden, Australia and Germany have also experienced a substantial increase (43-57\%) in $P_{\text {post }}$. On the other hand, $P_{\text {post }}$ has substantially decreased in the Netherlands, from $2.01 \%$ to $0.88 \%$ (a $56 \%$ decrease). Canada and the United States also shows a small (10-19\%) decline in $P_{\text {post }} . P_{\text {post }}$ has remained relatively stable in Norway. 
Table 2. Trends of Post-Tax-Transfer Poverty and Its' Components

\begin{tabular}{|c|c|c|c|c|c|c|}
\hline Country & & Wave 1 & Wave 2 & Wave 3 & Wave 4 & $\begin{array}{r}\text { Longest } \\
\text { Change } \\
\end{array}$ \\
\hline \multirow{5}{*}{ Australia } & Pre-tax-transfer poverty $\left(P_{p r e}\right)$ & 7.08 & 7.09 & 7.19 & 9.44 & 33.3 \\
\hline & Post-tax-transfer poverty $\left(P_{\text {post }}\right)$ & 1.57 & 1.47 & 1.58 & 2.27 & 44.8 \\
\hline & Effectiveness & 5.52 & 5.62 & 5.62 & 7.19 & 30.1 \\
\hline & Size of welfare state & 7.70 & 7.86 & 8.22 & 10.18 & 32.2 \\
\hline & Efficiency & 71.7 & 71.5 & 68.4 & 70.6 & -1.6 \\
\hline \multirow{5}{*}{ Canada } & Pre-tax-transfer poverty & 5.32 & 5.64 & 6.33 & 7.04 & 32.2 \\
\hline & Post-tax-transfer poverty & 1.69 & 1.52 & 1.43 & 1.37 & -18.5 \\
\hline & Effectiveness & 3.65 & 4.17 & 4.91 & 5.67 & 55.5 \\
\hline & Size of welfare state & 6.45 & 7.67 & 9.69 & 10.80 & 67.6 \\
\hline & Efficiency & 56.6 & 54.3 & 50.7 & 52.5 & -7.2 \\
\hline \multirow{5}{*}{ Denmark } & Pre-tax-transfer poverty & & 8.34 & 9.60 & & 15.2 \\
\hline & Post-tax-transfer poverty & & 1.33 & 1.15 & & -14.0 \\
\hline & Effectiveness & & 7.09 & 8.52 & & 20.2 \\
\hline & Size of welfare state & & 15.92 & 15.13 & & -4.9 \\
\hline & Efficiency & & 44.5 & 56.3 & & 26.4 \\
\hline \multirow{5}{*}{ Finland } & Pre-tax-transfer poverty & & 3.49 & 3.40 & 4.92 & 40.8 \\
\hline & Post-tax-transfer poverty & & 0.50 & 0.50 & 0.42 & -17.1 \\
\hline & Effectiveness & & 3.04 & 2.96 & 4.56 & 49.9 \\
\hline & Size of welfare state & & 6.89 & 7.25 & 10.48 & 52.2 \\
\hline & Efficiency & & 44.2 & 40.8 & 43.5 & -1.5 \\
\hline \multirow{5}{*}{ Germany } & Pre-tax-transfer poverty & 7.47 & 8.64 & 7.91 & 8.68 & 16.3 \\
\hline & Post-tax-transfer poverty & 0.65 & 0.55 & 0.70 & 0.93 & 42.7 \\
\hline & Effectiveness & 6.95 & 8.13 & 7.24 & 7.80 & 12.3 \\
\hline & Size of welfare state & 16.01 & 17.06 & 15.02 & 16.83 & 5.1 \\
\hline & Efficiency & 43.4 & 47.6 & 48.2 & 46.4 & 6.8 \\
\hline \multirow{5}{*}{ Netherlands } & Pre-tax-transfer poverty & 9.31 & 8.72 & 7.54 & 6.62 & -28.9 \\
\hline & Post-tax-transfer poverty & 2.01 & 1.13 & 1.31 & 0.88 & -56.0 \\
\hline & Effectiveness & 7.35 & 7.84 & 6.35 & 5.80 & -21.1 \\
\hline & Size of welfare state & 15.31 & 16.18 & 13.26 & 11.56 & -24.5 \\
\hline & Efficiency & 48.0 & 48.4 & 47.9 & 50.2 & 4.5 \\
\hline \multirow{5}{*}{ Norway } & Pre-tax-transfer poverty & 6.46 & 5.98 & 6.13 & 7.45 & 15.2 \\
\hline & Post-tax-transfer poverty & 0.74 & 0.59 & 0.62 & 0.80 & 8.8 \\
\hline & Effectiveness & 5.77 & 5.42 & 5.54 & 6.69 & 16.1 \\
\hline & Size of welfare state & 11.08 & 10.01 & 11.43 & 13.27 & 19.8 \\
\hline & Efficiency & 52.0 & 54.2 & 48.5 & 50.4 & -3.1 \\
\hline \multirow{5}{*}{ Sweden } & Pre-tax-transfer poverty & 9.37 & 9.79 & 11.49 & 10.44 & 11.4 \\
\hline & Post-tax-transfer poverty & 0.82 & 1.21 & 1.04 & 1.29 & 57.2 \\
\hline & Effectiveness & 8.74 & 8.92 & 10.52 & 9.25 & 5.9 \\
\hline & Size of welfare state & 21.01 & 19.60 & 24.07 & 22.53 & 7.2 \\
\hline & Efficiency & 41.6 & 45.5 & 43.7 & 41.1 & -1.3 \\
\hline \multirow{5}{*}{ U.K. } & Pre-tax-transfer poverty & 7.20 & 10.19 & 8.75 & 10.13 & 40.7 \\
\hline & Post-tax-transfer poverty & 0.88 & 1.51 & 1.38 & 1.54 & 75.7 \\
\hline & Effectiveness & 6.39 & 8.86 & 7.50 & 8.69 & 35.9 \\
\hline & Size of welfare state & 11.46 & 16.15 & 11.41 & 14.05 & 22.7 \\
\hline & Efficiency & 55.8 & 54.9 & 65.7 & 61.8 & 10.8 \\
\hline \multirow{5}{*}{ U.S. } & Pre-tax-transfer poverty & 6.24 & 6.47 & 6.81 & 6.08 & -2.7 \\
\hline & Post-tax-transfer poverty & 2.64 & 2.92 & 2.81 & 2.37 & -10.1 \\
\hline & Effectiveness & 3.73 & 3.75 & 4.10 & 3.78 & 1.4 \\
\hline & Size of welfare state & 7.04 & 7.07 & 8.11 & 7.37 & 4.7 \\
\hline & Efficiency & 52.9 & 53.1 & 50.6 & 51.3 & -3.2 \\
\hline
\end{tabular}

1. Percentage change: (Latest year-Earliest year)/Earliest year

Source: Author's calculation from the LIS database. 
Which factors affect these changes in poverty during this period? Table 2 shows that $P_{\text {pre }}$ has increased in every country except the Netherlands and the United States. The amount of increase in $P_{\text {pre }}$ is fairly large in the United Kingdom (from $7.20 \%$ to $10.13 \%$, or a $40.7 \%$ increase), Australia (from $7.08 \%$ to $9.44 \%$, or a $33.3 \%$ increase), and Canada (from $5.32 \%$ to $7.04 \%$, or a $32.2 \%$ increase). Germany, Norway and Sweden experienced $11-16 \%$ increase in $P_{p r e}$. In the United States, $P_{\text {pre }}$ remained relatively stable, at 6.2-6.8\%. Only the Netherlands has experienced a substantial decline in $P_{\text {pre }}$, from $9.31 \%$ to $6.62 \%$ (a $28.9 \%$ decrease).

Table 2 also shows that the poverty reduction effectiveness of taxes and transfers has increased in most welfare states. In particular, the anti-poverty effectiveness of the Canadian taxtransfer system has greatly increased. In the early 1980s, the Canadian tax-transfer system (exactly speaking, positive net transfers) reduced the pre-tax-transfer poverty gap ratio by 3.65 percent point. In the mid-1990s, it reduced the poverty gap ratio by 5.67 percent point, which is $55.5 \%$ greater than in the early $1980 \mathrm{~s}$. Although pre-tax-transfer poverty has also substantially increased in Canada, a much greater increase in the anti-poverty effectiveness enables Canada to achieve a decrease in post-tax-transfer poverty.

In other countries such as Australia, Germany, Norway, Sweden and the United Kingdom, the anti-poverty effectiveness has also increased. However, the increase is not so large enough to offset the increase in pre-tax-transfer poverty. As a result, the post-tax-transfer poverty has increased in these countries.

What is the primary source of the increasing trend of the anti-poverty effectiveness? The last two rows in each panel of Table 2 show the trends of the two components of the anti-poverty effectiveness-size and efficiency. As shown in the table, the poverty reduction efficiency has in general remained quite stable. In most countries, it fluctuates within a very small range. Only the 
United Kingdom shows a moderate increase in efficiency, from 55.8\% in 1979 to $65.7 \%$ in 1991 and $61.8 \%$ in 1995.

Since the poverty reduction efficiency has not changed much, increases in the antipoverty effectiveness is mainly due to increases in the size of the welfare state. Table 2 suggests that the size of the welfare state has increased in most countries except the Netherlands. Canada shows the greatest increase in the size of the welfare state, from $6.45 \%$ to $10.8 \%$ (a $67.6 \%$ increase). In Australia, the United Kingdom and Norway, the size of the welfare state has also increased in a substantial amount (20-32\%). Increase in the size of the welfare state is relatively small (5-7\%) in Germany, Sweden and the United States. In the Netherlands, the size of the welfare state has decreased from $15.31 \%$ to $11.56 \%$ (a $24.5 \%$ decrease).

Overall, the trends of the components of post-tax-transfer poverty can be summarized as follows. First, in most of welfare states, pre-tax-transfer poverty has increased during the 1980s and early 1990s. Second, most countries have increased the size of the welfare state during the same period. However, in many cases, the increase in the size of the welfare state is not so large enough to offset the increase in pre-tax-transfer poverty. As a result, post-tax-transfer poverty has also-more or less-increased in these countries. Third, in general, the poverty reduction efficiency has not changed much. Fourth, Canada, the Netherlands and the United States are different to other countries. Although Canada has also experienced a substantial increase in pretax-transfer poverty, post-tax-transfer poverty has—on the contrary-decreased, owing to a much greater increase in the size of the welfare state. Unlike other countries, the Netherlands has reduced the size of the welfare state. However, the Netherlands has experienced a decrease in post-tax-transfer poverty, mainly due to a decrease in pre-tax-transfer poverty. Post-tax-transfer 
poverty in the United States has not changed much, because all three components-pre-taxtransfer poverty, size, and efficiency—have remained relatively stable.

\section{Concluding Remarks-Toward Future Research}

This study analyzes the anti-poverty achievements of taxes and income transfers in western welfare states. Major findings of this study are as follows. First, the extents of poverty differ widely across welfare states and parts of these differences arise from differences in the anti-poverty effectiveness of the tax-transfer system. Second, differences in the anti-poverty effectiveness are largely attributed to the overall level of redistributional efforts rather than to the degree of selectivity or the poverty reduction efficiency of the tax-transfer system. Third, most of welfare states have experienced an increase in market-generated poverty (pre-tax-transfer poverty) during the 1980s and early 1990s. Fourth, during the same period, welfare states-in general-have increased the overall level of welfare benefits ${ }^{15}$. However, in most cases, the expansion of welfare benefits is not so large enough to offset the increase in market-generated poverty. Fifth, although some studies report that there has been a trend of stricter eligibility for welfare benefits and increasing selectivism among welfare states (Morris, 1988; OECD, 1994), micro evidence suggests that the poverty reduction efficiency of taxes and transfers has remained fairly stable.

In spite of these findings, a critical issue remains still unanswered. According to the standard approach of pre-post comparison, a higher level of the size of the welfare state and/or a higher level of the poverty reduction efficiency obviously yields a larger reduction of poverty, and thereby, leads to a lower level of post-tax-transfer poverty. In this approach, the level of pre- 
tax-transfer poverty is treated as given. In other words, an implicit assumption of the standard approach is that taxes and transfers do not affect the level of pre-tax-transfer poverty.

This assumption may be unrealistic. Even studies based on the standard approach have often recognized the weaknesses of this assumption (e.g., Aguilar and Gustaffson, 1987; Förster, 1993; Lambart and Pfähler, 1988; Ringen and Uusitalo, 1992). Taxation and welfare transfers are likely to affect diverse aspects of human behavior, and hence, pre-tax-transfer income and poverty ${ }^{16}$. Among the potential feedback effects, the opponents of the welfare state have often criticized welfare programs for their detrimental effects on work effort. According to the theories in labor economics, both the size and the efficiency aspects of welfare benefits may affect the work incentives of recipients. First, a larger welfare state tends to provide more benefits to the poor. Assuming that leisure is a normal good, an increase in non-labor income (welfare benefits) is likely to reduce labor supply. Second, a higher level of the poverty reduction efficiency can be achieved by a more targeted (income-tested) welfare system. In general, income-tested welfare programs tend to reduce benefits as the earnings of the recipients' increase. Therefore, labor economists have argued that by imposing very high marginal tax rate on their earnings, incometested benefits may reduce the work effort of the recipients. If these arguments are true, the level of pre-tax-transfer poverty may not be exogenous. To the extent that pre-tax-transfer poverty is affected by the size and the efficiency of taxes and transfers, the standard approach overemphasizes the 'net' anti-poverty effect of the welfare state.

The results of this study suggest this possibility. As described earlier, there is a strong correlation between the level of pre-tax-transfer poverty and the anti-poverty effectiveness. In other words, countries with a higher level of the size of the welfare state and/or the poverty reduction efficiency are likely to have a higher level of pre-tax-transfer poverty. However, from 
this cross-sectional relationship, one can not ascertain unambiguously "what causes what"

(Markus, 1979). Although the above arguments may suggest the size and the efficiency of the welfare state may affect pre-tax-transfer poverty, there may be cases in which the causal order is in the opposite direction. For instance, an increase in unemployment implies an increase in pretax-transfer poverty. At the same time, it necessitates increases in welfare expenditures on unemployment benefits, which results in an increase in the size of the welfare state. If this is the case, the level of pre-tax-transfer poverty causes the size of the welfare state. In any case, the potential endogeniety of pre-tax-transfer poverty is a challenge for future research.

\section{Endnotes:}

${ }^{1}$ In relation to the objectives of this study, two limitations are worth pointing out. First, in this study, welfare states are assessed in respect to their achievements in poverty alleviation. Although poverty alleviation is one of the most important goals of social policy in welfare states, it is not the only objective. Other important goals include 1) improving social security against the risk of life such as retirement, sickness, disability, or unemployment (income smoothing), 2) achieving greater equality among social classes, genders, or different types of families (inequality reduction), 3) establishing human dignity and social solidarity, 4) vertical and horizontal equity, 5) macro and micro economic efficiency, and 6) administrative feasibility (Atkinson, 1995; Barr, 1992; Sandmo, 1991). Any attempt to assess the overall achievement of the welfare state should take all of these diverse goals into consideration.

Second, the welfare state makes diverse efforts to increase the living standard of the poor population. In addition to direct cash benefits, welfare policies include health care, education and training, food, housing, interventions to the labor market, and other welfare services. Moreover, government may encourage occupational welfare or private charity through tax exemption on these expenditures. Although all of these policies are more or less related to the poverty outcomes of a country, this study limits the analysis to the anti-poverty effect of taxes and governmentprovided income transfers. This is because taxes and income transfers are major tools for income redistribution in the welfare state and prior studies suggest that the cross-national variation of poverty is highly related to differences in the tax-transfer system (Förster, 1993; Mitchell, 1991; Ringen, 1987).

${ }^{2}$ A standard approach to analyze the anti-poverty effect of taxes and income transfers is to compare pre-tax-transfer poverty and post-tax-transfer poverty. To estimate these two measures of poverty, scholars distinguish diverse sources of household income into two components. First, pre-tax-transfer income (or market income) is defined by the sum of income from market sources (such as wages and salaries, self-employed income, capital income, benefits from private pensions or insurances, and other private transfers). From pre-tax-transfer income, subtracting income taxes and social security taxes and adding welfare transfers lead to post-tax-transfer income (or disposable income). In this approach, the difference between pre-tax-transfer income and post-tax-transfer income is defined as the "redistributive" effect of the welfare state (or more precisely, of the tax-transfer system).

${ }^{3}$ These countries are the Czech Republic, Hungary, Poland, Russia, the Slovak Republic, Israel, and Taiwan.

${ }^{4}$ Data of Italy, Luxembourg, and Spain provide only net income variables, which makes it impossible to calculate pre-tax-transfer income. Tax information in the data of France is incomplete.

${ }^{5}$ Countries analyzed in this study are Australia, Belgium, Canada, Denmark, Finland, Germany, the Netherlands, Norway, Sweden, the United Kingdom, and the United States. 
${ }^{6}$ Some criticize that this relative definition of poverty measures inequality rather than poverty (Blackburn, 1993; Teekens and Zaidi, 1990). They argue that the relative poverty definition only reflects cross-national difference in the income distribution and ignores difference in the overall economic prosperity. Based on this critique, they propose to use the absolute poverty line of a particular country and to convert it to other countries using the purchasing power parities (PPP). However, at least in developed countries, there is a broad consensus that poverty is not merely a lack of resources for basic physical needs but should be defined as a deprivation from an acceptable way of life in the society. Since many countries do not proclaim the official poverty threshold, the median income may provide a good proxy of the dominant standard of living in a society, and thereby, poverty can be measured by a substantial departure from this standard. Another, more practical critique to the $50 \%$ median income is the choice of a particular percentile is completely arbitrary. Yet, prior studies suggest that the cross-national comparison of poverty is not very sensitive to the choice of alternative percentiles (Förster, 1993).

${ }^{7}$ In existing cross-national studies, the OECD equivalent scale has been the most frequently used. The OECD scale sets 1.0 for the head of household, 0.7 for each additional adult, and 0.5 for each child. Since it gives the same weight to the second adult and the third or fourth adult, the OECD scale has been criticized for assuming no economies of scale except between the first and second adult. Reviewing an extensive volume of literature, the National Research Council proposed the following equivalent scale:

$$
\text { Equivalent Scale }=(A+0.7 \times C)^{0.7}
$$

where $A$ is the number of adults and $C$ is the number of children in the household. For the most part, the crossnational comparison of poverty is not very sensitive to using alternative equivalent scales (Buhmann, Rainwater, Schmaus, and Smeeding, 1988).

${ }^{8}$ First, the head-count ratio treats poverty as a dichotomous condition and does not reflect the intensity of poverty among the poor. A $\$ 1,000$ government transfer to a poor person obviously increases the well-being of the recipient. However, this transfer does not necessarily result in a reduction of poverty if poverty is measured by the head-count ratio. If the recipient's income after the transfer still remains below the poverty line, the head-count ratio would not decrease in spite of the transfer. Furthermore, given the level of government spending, the most efficient way of reducing the head-count ratio is to pull the highest possible number of the poor out of poverty. This is achieved by concentrating welfare spending on those with income just below the poverty line (i.e., the richest poor) rather than on the poorest poor, which is intuitively less appealing. Another weakness of the head-count ratio is that it is quite sensitive to where the poverty line is set. A typical poverty line used in cross-national studies, $50 \%$ of the median income, is often criticized for being arbitrary. To reduce the effect of arbitrariness in the choice of the poverty line, it is preferable to use a poverty index which is not very sensitive to the poverty line.

${ }^{9}$ In a notational term, this is given by:

$$
\text { Poverty Gap Ratio }=\frac{1}{n \bar{Y}} \sum_{i=1}^{q}\left(z-y_{i}\right)
$$

where $q$ is the number of the poor, $n$ is total population size, $z$ is the poverty line, $\bar{Y}$ is the average post-tax-transfer income of a society, $y_{i}$ is the income of an individual $i$, and $i$ is a subscript for persons arrayed in the increasing order of their incomes.

${ }^{10}$ The proportion of the pre-tax-transfer poverty gap reduced by taxes and transfers [(Pre-Post)/Pre].

${ }^{11}$ If the size of the welfare state were defined by the average amount of net transfers rather than of "positive" net transfers, the value would be close to zero because positive values in lower income classes are likely to be offset by negative values in higher income classes.

${ }^{12}$ This is to adjust the measure to differences in family size across households.

${ }^{13}$ The poverty ranks of countries are slightly different between when poverty is measured by the head-count ratio and when measured by the poverty gap ratio. Appendix Table 1 compares poverty estimates between these two alternative measures of poverty. 
${ }^{14}$ It must be noted that the beta coefficients can inform us only of the relative-not absolute-importance, because there is a contribution of the interaction term of two variables that can not be disentangled.

${ }^{15}$ More precisely speaking, income transfers net of taxes.

${ }^{16}$ For a review of discussions on the potential effects of welfare transfers on socio-economic behaviors, see Danziger, Haveman, and Plotnick (1981) and Moffitt (1992).

Appendix Table 1. Comparison of Poverty Estimates (Head-Count Ratio versus Poverty Gap Ratio)

\begin{tabular}{|l|c|c|c|c|}
\hline \multirow{2}{*}{} & \multicolumn{2}{|c|}{ Head-Count Ratio (\%) } & \multicolumn{2}{c|}{ Poverty Gap Ratio (\%) } \\
\cline { 2 - 5 } & Pre & Post & Pre & Post \\
\hline Finland (1995) & 19.4 & $4.0(1)$ & 4.92 & 0.42 \\
Norway (1995) & 24.4 & $5.3(2)$ & 7.45 & 0.80 \\
Belgium (1992) & 28.8 & $5.0(3)$ & 11.61 & 0.83 \\
Netherlands (1994) & 20.1 & $5.6(4)$ & 6.62 & 0.88 \\
Germany (1994) & 25.6 & $6.9(7)$ & 8.68 & 0.93 \\
Denmark (1992) & 26.6 & $5.9(5)$ & 9.60 & 1.15 \\
Sweden (1995) & 33.3 & $6.1(6)$ & 10.44 & 1.29 \\
Canada (1994) & 24.7 & $10.7(8)$ & 7.04 & 1.37 \\
U.K. (1995) & 31.7 & $12.1(9)$ & 10.13 & 1.54 \\
Australia (1994) & 27.9 & $12.9(10)$ & 9.44 & 2.27 \\
U.S.A. (1997) & 24.2 & $16.6(11)$ & 6.08 & 2.37 \\
& & & & \\
Mean & 26.1 & 8.3 & 8.36 & 1.26 \\
CV & 0.157 & 0.471 & 0.238 & 0.461 \\
\hline
\end{tabular}

* Countries are sorted by the ascending order of the post-tax-transfer poverty gap ratio.

* Rank orders are in the parentheses.

Source: Author's calculation from the LIS database. 


\section{REFERENCES}

Aguilar, Renato and Björn Gustafsson (1987). "The Role of Public Transfers and Income Taxes: An International Comparison." LIS Working Paper \#10. Differdange, Luxembourg: CEPS/INSTEAD.

Atkinson, Anthony B. (1995). Incomes and the Welfare State: Essays on Britain and Europe. Cambridge, UK: Cambridge University Press.

Atkinson, Anthony, Lee Rainwater, and Timothy Smeeding (1995). Income Distribution in OECD Countries: Evidence from the Luxembourg Income Study. Paris: OECD.

Barr, Nicholas (1992). "Economic Theory and the Welfare State: A Survey and Interpretation." Journal of Economic Literature 30: 741-803.

Beckerman, Wilfred (1979). Poverty and the Impact of Income Maintenance Programmes in Four Developed Countries. Geneva: International Labour Office.

Blackburn, McKinley L. (1993). "International Comparisons of Income Poverty and Extreme Income Poverty." LIS Working Paper \#97. Differdange, Luxembourg: CEPS/INSTEAD.

Buhmann, Brigitte, Lee Rainwater, Guenther Schmaus and Timothy M. Smeeding (1988). "Equivalent Scales, Well-being, Inequality, and Poverty: Sensitivity Estimates across Ten Countries Using LIS." Review of Income and Wealth 34: 115-142.

Burniaux, Jean-Marc, Thai-Thanh Dang, Douglas Fore, Michael Förster, Macro Mira d'Ercole and Howard Oxley (1998). "Income Distribution and Poverty in Selected OECD Countries.” OECD Economic Department Working Paper \#189. Paris: OECD.

Citro, Constance F. and Robert T. Michael (1995). Measuring Poverty: A New Approach. Washington D.C.: National Academy Press.

Danziger, Sheldon, Robert Haveman, and Robert Plotnick (1981). "How Income Transfer Programs Affect Work, Savings, and the Income Distribution: A Critical Review." Journal of Economic Literature 19(3) : 975-1028.

Förster, Michael F. (1993). "Comparing Poverty in 13 OECD Countries: Traditional and Synthetic Approaches." LIS Working Paper \#100. Differdange, Luxembourg: CEPS/INSTEAD.

Hauser, Richard (1992). "Problems of Comparative Social Policy Analysis: The Case of Pension Systems and Income Security for the Elderly." in Daniel J. Slottje and Timothy M. Smeeding (eds.). Research on Economic Inequality, vol. 3: International Comparisons of Economic Inequality. Greenwich, CT: JAI Press. 
Jäntti, Markus and Sheldon Danziger (1998) "Income Poverty in Advanced Countries." in A. B. Atkinson and F. Bourguignon (eds.) Handbook on Income Distribution. New York: Elsevier-North Holland Publishers, forthcoming.

Lambart, Peter J. and Whihelm Pfähler (1988). "On Aggregate Measures of the Net Redistributive Impact of Taxation and Government Expenditure." Public Finance Quarterly 16(2): 178-202.

Lisle, Edmond A. (1985). "Validation in the Social Sciences by International Comparison." International Social Science Journal 103 : 19-29.

Markus, Gregory B. (1979). Analyzing Panel Data. London: Sage Publications.

Mitchell, Deborah (1991). Income Transfers in Ten Welfare States. Brookfield, VT: Gower Publishing Company.

Mitchell, Deborah, Ann Harding, and Fred Gruen (1994). "Targeting Welfare." Economic Record 70(210): 315-340.

Moffitt, Robert (1992). "Incentive Effects of the U.S. Welfare System: A Review." Journal of Economic Literature 30; 1-61.

Morris, Robert (1988). "Changing Patterns of Public Social Welfare Policy in Nine Countries, 1975-1986: Predicting Future Trends.” in R. Morris (ed,) Testing the Limits of Social Welfare: International Perspectives on Policy Changes in Nine Countries. Hanover: University Press of New England.

Organization for Economic Co-operation and Development (1994). New Orientations for Social Policy. Paris: OECD.

Ringen, Stein (1987). "Poverty in the Welfare State?" in Robert Erikson, Erik Jorgen Hansen, Stein Ringen and Hannu Uusitalo (eds.) The Scandinavian Model: Welfare States and Welfare Research. Armonk, NY: M. E. Sharpe.

Ringen, Stein and Hannu Uusitalo (1992). "Income Distribution and Redistribution in the Nordic Welfare States." in Jon Eivind Kolberg (ed.) The Study of Welfare State Regimes. New York: M. E. Sharpe.

Sandmo, Agnar (1991). "Economists and the Welfare State." European Economic Review 35 : 213-239.

Smeeding, Timothy M. (1992). "Cross-National Analysis of Social Policy and Economic Inequality: Value, Resources, and Challenge". in Daniel J. Slottje and Timothy M. Smeeding (eds.). Research on Economic Inequality, vol. 3: International Comparisons of Economic Inequality. Greenwich, CT: JAI Press. 
Teekens, Rudolf and Asghar Zaidi (1990). "Relative and Absolute Poverty in the European Community." in Rudolf Teekens and Bernard M. S. Van Praag (eds.) Analysing Poverty in the European Community: Policy Issues, Research Options and Data Sources. Luxembourg: Office for Official Publications of the European Community.

Weisbrod, Burton A. (1969). "Collective Action and the Distribution of Income: A Conceptual Approach." in U.S. Congress, Joint Economic Committee. The Analysis and Evaluation of Public Expenditures: The PPB System. Washington DC.

Wilensky, Herold L., Gregory M. Luebbert, Susan Reed Hahn, and Adrienne M. Jamieson (1987). "Comparative Social Policy: Theories, Methods, Findings." in Dierkes, Meinolf, Hans N. Weiler and Ariane Berthoin Antal (eds.). Comparative Policy Research: Learning from Experience. New York: St. Martin's Press. 